\title{
Evaluation of important buildings anti-terrorism capability based on fuzzy analytic hierarchy process
}

\author{
REN Cai-qing 1,2,a, Huo Li-fei ${ }^{2, b}, \mathrm{HU}$ Qi-gao ${ }^{3, \mathrm{c}}$ \\ ${ }^{1}$ School of Resources and Safety Engineering, Central South University, Changsha 410083, China \\ ${ }^{2}$ CCCC Third Highway Engineering CO.,LTD, Beijing 101118, China \\ ${ }^{3}$ School of Basic Education for Commanding Officers, National University of Defense Technology, \\ Changsha 410072,China \\ arencaiqing@csu.edu.cn, b53824343@qq.com, c13308492427@133.com
}

\begin{abstract}
Keywords: anti-terrorist attack, capability evaluation, fuzzy analytic hierarchy process, building Abstract. Improve the anti-terrorism capability is one of the most effective ways to ensure public security under the current situation of terrorist threat. A fuzzy analytic hierarchy process (FAHP) to analyze and evaluate the important buildings anti-terrorism capability is proposed. It establishes the hierarchy of capability index system in anti-terrorism capability and determines the weights of various factors sequentially to create a comprehensive capability evaluation model. The factors were sorted according to their impacts on the overall capability level. Results obtained from the analysis suggested that the evacuation facilities, emergency facilities and attack prevention contributed to the anti-terrorism capability more than any other sub-factors. The rationality and feasibility of the proposed model were proved by applying to the anti-terrorism capability evaluation process.
\end{abstract}

\section{Introduction}

There is a rampant increase in terrorist attack all over the world, especially the terrorist attacks to the important buildings with the aim of maximizing media attention and psychological impact on the public [1,2]. Evaluation of important buildings' anti-terrorism capability is critical to ensure security and architectural design [3]. However, anti-terrorist attacks on important buildings have complex characteristics as reflected by the following facts: there is a lack of adequate intelligence support to tackle the menaces, including the composition of terrorists, attack targets, attack date and its motivations [4,5]. The building's anti-terrorism capabilities are diverse and difficult to quantitative evaluate. Because of various influence factors such as the government support, emergency evacuation, rescue and reconstruction. Terrorist attacks are well planned and implemented secretly [6].

It has been found that poor intelligence is very detrimental to anti-terrorism attack [7]. It has also been shown that lack of personnel, technology, equipment will make it more difficult to counter terrorist attacks. [8]. However, there have been limited researches and efforts that have been conducted to evaluate the anti-terrorism capability of important buildings. Additionally, various influential factors require the coupling in the anti-terrorism capability to get the comprehensive measurement and ensure that the proposed method and model are feasible and effective.. Evaluation of important buildings anti-terrorism capability is significant to quantify the effect of multiple factors and to improve the effectiveness of anti-terrorist attack capacity development. With this aim, fuzzy analytic hierarchy process (FAHP) was applied in the Evaluation of important buildings anti-terrorism capability in this article. Taking a case as an example, the anti-terrorism capability analysis hierarchy model of important buildings was established and the capability level was comprehensively evaluated. The results provide the references for improving anti-terrorism capability of important building.

\section{Methodology}

The analytic hierarchy process (AHP) is one of the most commonly used multi-attribute decision-making models, which was proposed in the 1970s [9]. However, AHP involves human 
subjectivity, which introduces vagueness and uncertainty. There has been plenty of research that blends fuzzy logic, which is a popular method of incorporating uncertain attributes into the decision-making process, with AHP to form a model for risk assessment [10]. These risk evaluation models are widely applied to multiple fields such as modular product designs [11], information technology projects[12], power transformers[13], and behavior-based safety management[14]. The research on anti-terrorism capability evaluation of important buildings is less, though FAHP is a practical method for quantitative evaluation.

This paper combines the AHP and fuzzy theory in a different way using the following six steps:

Step 1: Establish the hierarchy structure model.

Step 2: Define the relative degrees of importance of the capability influential factors.

Step 3: Calculate the comprehensive degree of importance.

Step 4: Define the membership degree.

Step 5: Comprehensive evaluation.

The membership degree of each evaluation factor $\mu_{A}\left(x_{i}\right)$ and the comprehensive importance of each factor $\left(W_{i}\right)$ were calculated and the comprehensive evaluation was performed. The evaluation function is shown in Eq. 1:

$$
T_{\text {ORL }}=\sum_{i=1}^{n} W_{i} \mu\left(x_{i}\right)
$$

Step 6: anti-terrorism capability management of important buildings.

Based on the above procedure, the process flow for the calculation of the anti-terrorism capability level is shown in Fig. 1.

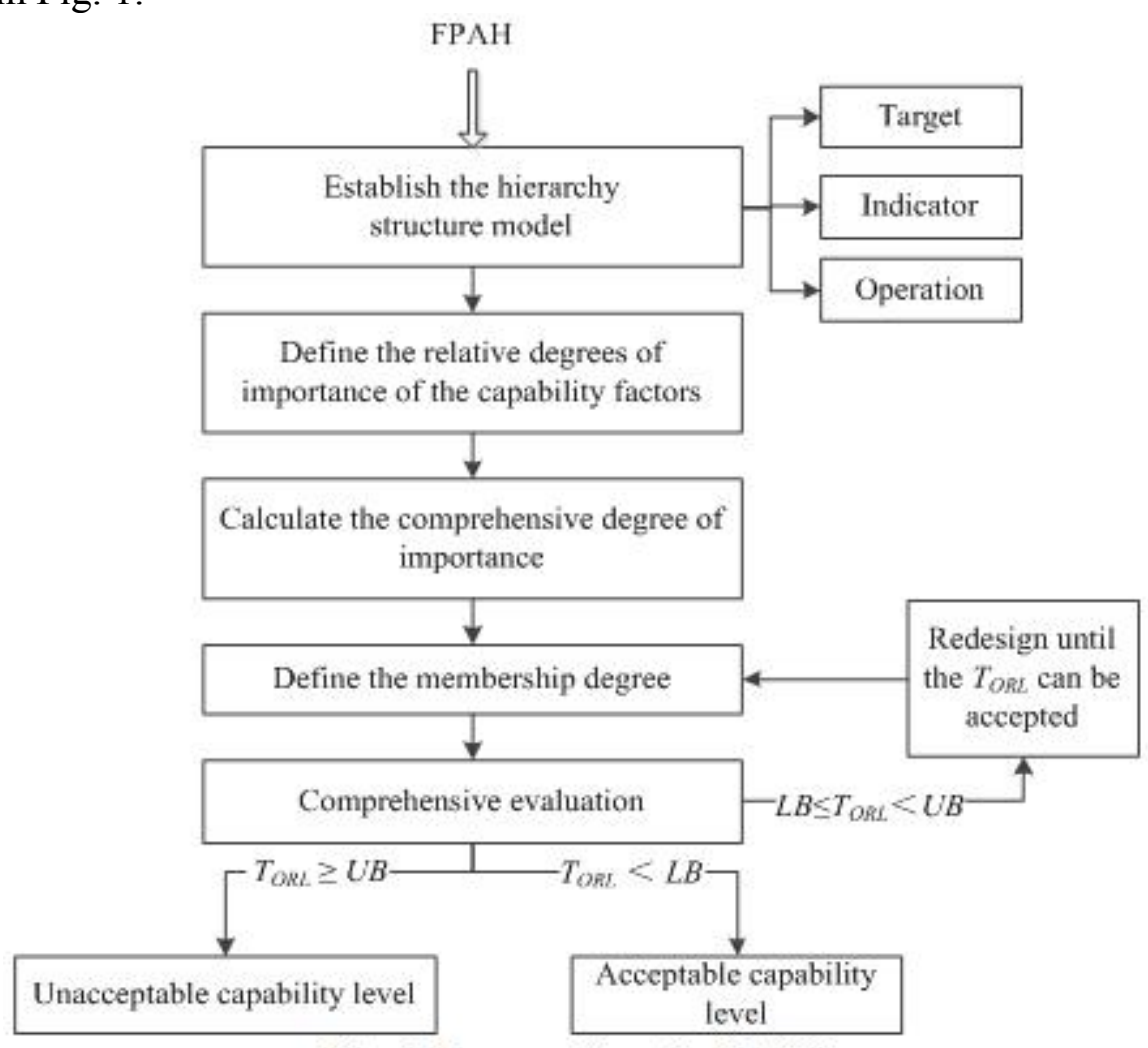

Fig. 1 Process flow for FAHP

\section{Anti-terrorism attack capability assessment}

(1) Establish the evaluation index system and hierarchy structure model

In this paper, the evaluation objects and data were sourced from anti-terrorism teaching case library of the National University of Defense Technology. The evaluation index system and hierarchy structure model shown in Fig. 2 are based on the characteristics of important buildings and the combination of existing data and knowledge gained from experts. 


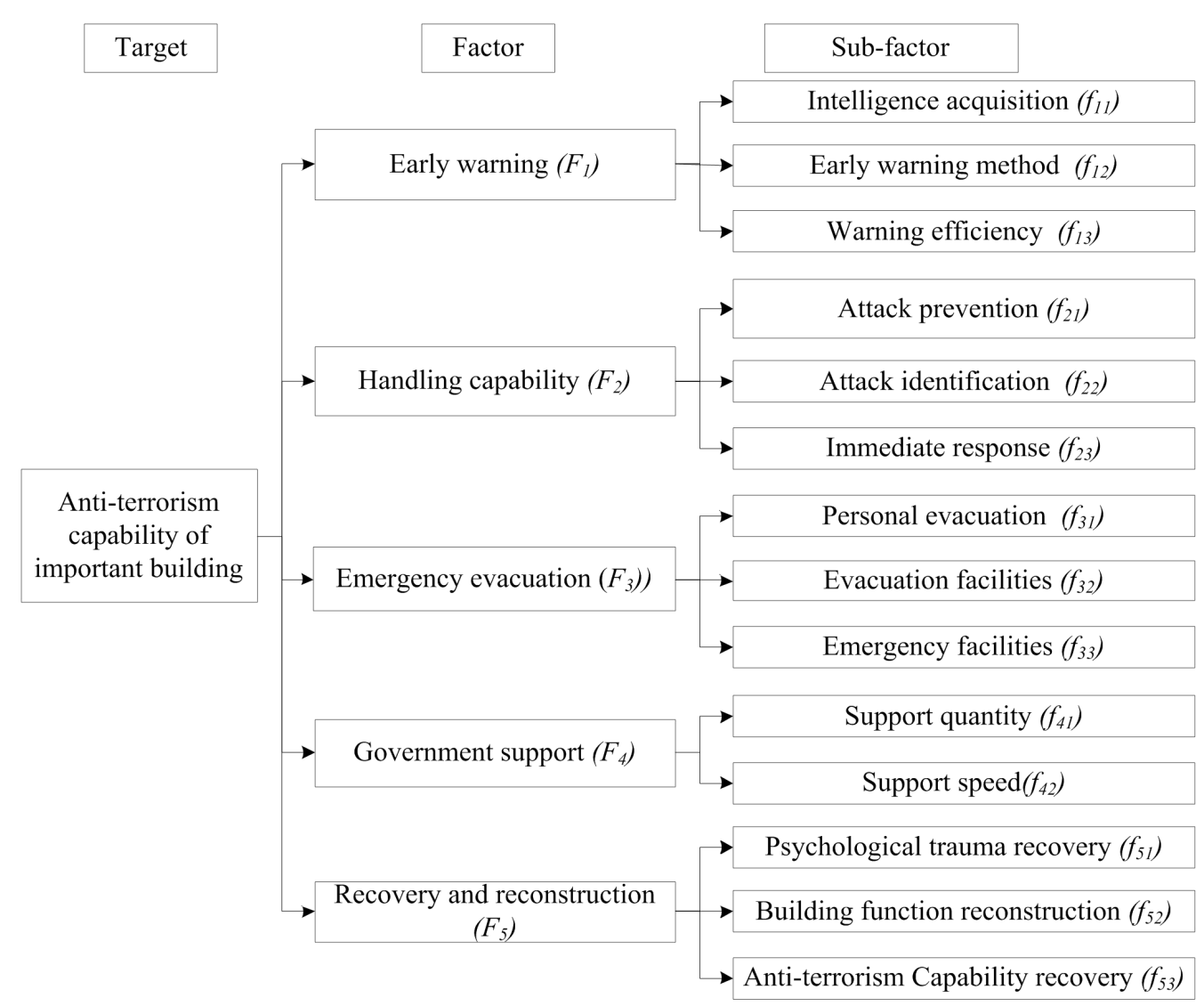

Fig.2 Hierarchy structure model of anti-terrorism capability

(2) Define the relative degrees of importance of the capability influential factors

Using the hierarchy structure model shown in Fig.2, design a questionnaire to collect basic data for anti-terrorism capability evaluation. Statistical analysis was carried out on the response obtained for the questionnaire which is based on a judgment matrix. The fuzzy linguistic scale method was adopted to compare the risk factors. The judgment matrices created in this study are shown in Table 1-Table 6.

Table 1 Judgment matrix for factors influencing anti-terrorism capability

\begin{tabular}{|c|c|c|c|c|c|}
\hline$T$ & $F_{1}$ & $F_{2}$ & $F_{3}$ & $F_{4}$ & $F_{5}$ \\
\hline$F_{1}$ & 1 & $3 / 4$ & $1 / 4$ & $2 / 3$ & 3 \\
\hline$F_{2}$ & $4 / 3$ & 1 & $1 / 3$ & $2 / 3$ & 3 \\
\hline$F_{3}$ & 4 & 3 & 1 & $3 / 2$ & 7 \\
\hline$F_{4}$ & $3 / 2$ & $3 / 2$ & $2 / 3$ & 1 & 4 \\
\hline$F_{5}$ & $1 / 3$ & $1 / 3$ & $1 / 7$ & $1 / 4$ & 1 \\
\hline
\end{tabular}

Table 2 Judgment matrix for the sub-factors of early warning

\begin{tabular}{|c|c|c|c|}
\hline$F_{1}$ & $f_{11}$ & $f_{12}$ & $f_{13}$ \\
\hline$f_{11}$ & 1 & 3 & 5 \\
\hline$f_{12}$ & $1 / 3$ & 1 & 2 \\
\hline$f_{13}$ & $1 / 5$ & $1 / 2$ & 1 \\
\hline
\end{tabular}

Table 3 Judgment matrix for sub-factors of handling capability

\begin{tabular}{|c|c|c|c|}
\hline$F_{2}$ & $f_{21}$ & $f_{22}$ & $f_{23}$ \\
\hline$f_{21}$ & 1 & 5 & 3 \\
\hline$f_{22}$ & 2 & 1 & 3 \\
\hline$f_{23}$ & $1 / 3$ & $1 / 3$ & 1 \\
\hline
\end{tabular}


Table 4 Judgment matrix for sub-factors of emergency evacuation

\begin{tabular}{|c|c|c|c|}
\hline$F_{3}$ & $f_{31}$ & $f_{32}$ & $f_{33}$ \\
\hline$f_{31}$ & 1 & $1 / 2$ & $1 / 2$ \\
\hline$f_{32}$ & 2 & 1 & $2 / 3$ \\
\hline$f_{33}$ & 2 & $3 / 2$ & 1 \\
\hline
\end{tabular}

Table 5 Judgment matrix for sub-factors of government support

\begin{tabular}{|c|c|c|}
\hline$F_{4}$ & $f_{41}$ & $f_{42}$ \\
\hline$f_{41}$ & 1 & $2 / 3$ \\
\hline$f_{42}$ & $3 / 2$ & 1 \\
\hline
\end{tabular}

Table 6 Judgment matrix for sub-factors of recovery and reconstruction

\begin{tabular}{|c|c|c|c|}
\hline$F_{5}$ & $f_{51}$ & $f_{52}$ & $f_{53}$ \\
\hline$f_{51}$ & 1 & 3 & 4 \\
\hline$f_{52}$ & $1 / 3$ & 1 & 2 \\
\hline$f_{53}$ & $1 / 4$ & $1 / 2$ & 1 \\
\hline
\end{tabular}

There are many calculation methods to determine the weights of various factors in the FAHP process[15]. The root method[16] was used to calculate and judge the eigenvectors in the judgment matrix and perform consistency checks in this study. The calculation results are shown in Table 7.

Table 7 Judgment matrix eigenvectors and consistency checks

\begin{tabular}{|c|c|c|c|c|c|}
\hline $\begin{array}{c}\text { Judgement } \\
\text { Matrix }\end{array}$ & Eigenvector & $\lambda_{\max }$ & $\begin{array}{c}\text { Concordance } \\
\text { index }(C I)\end{array}$ & $\begin{array}{c}\text { Random } \\
\text { consistency index } \\
\text { (RI) }\end{array}$ & $\begin{array}{c}\text { Consistency } \\
\text { ratio }(C R)\end{array}$ \\
\hline$T-F$ & {$\left[\begin{array}{llllll}0.133 & 0.158 & 0.425 & 0.231 & 0.053\end{array}\right]^{\mathrm{T}}$} & 5.039 & 0.010 & 1.119 & 0.009 \\
\hline$F_{1-f}$ & {$\left[\begin{array}{llll}0.648 & 0.230 & 0.122\end{array}\right]^{\mathrm{T}}$} & 3.004 & 0.002 & 0.515 & 0.004 \\
\hline$F_{2-f}$ & {$\left[\begin{array}{llll}0.333 & 0.528 & 0.140\end{array}\right]^{\mathrm{T}}$} & 3.054 & 0.027 & 0.515 & 0.052 \\
\hline$F_{3}-f$ & {$\left[\begin{array}{llll}0.199 & 0.347 & 0.455\end{array}\right]^{\mathrm{T}}$} & 3.018 & 0.009 & 0.515 & 0.018 \\
\hline$F_{4-f}$ & {$\left[\begin{array}{lll}0.400 & 0.600\end{array}\right]^{\mathrm{T}}$} & 2.000 & 0.000 & l & / \\
\hline$F_{5}-f$ & {$\left[\begin{array}{llll}0.625 & 0.238 & 0.136\end{array}\right]^{\mathrm{T}}$} & 3.018 & 0.009 & 0.515 & 0.018 \\
\hline
\end{tabular}

(3) Calculate the comprehensive degree of importance

Starting from the highest level, the relative importance of each factor as compared to the upper level was calculated and the calculation results were shown in Table 7. Then, the comprehensive importance and membership degrees of each factor of anti-terrorism capability evaluation are calculated and shown in Table 8 .

(4) Define the membership degree

The membership function of each influence factor was established by an assignment method based on logical reasoning and the membership degree was determined. The appropriate fuzzy distribution was selected from the standard fuzzy distribution based on the characteristics of anti-terrorism capability influential factor and relevant suggestions from experts in the field of anti-terrorism. Next, calculate the relevant parameters according to the experience of the specified membership function as determined from the evaluation index. The membership function of the factor can be determined by Eq.2. The membership functions of the other factors can be determined similarly.

$$
A(x)=\left\{\begin{aligned}
1, & x>0.9 \\
\frac{x-0.1}{0.9-0.1}, & 0.1 \quad x \quad 0.9 \\
0, & x<0.1
\end{aligned}\right.
$$


Table 8 Comprehensive degrees of importance and membership degrees of influential factors

\begin{tabular}{|c|c|c|c|c|c|c|c|c|}
\hline \multirow{2}{*}{\multicolumn{2}{|c|}{$\begin{array}{c}\text { Anti-terrorism } \\
\text { operational risk }\end{array}$}} & $F_{1}$ & $F_{2}$ & $F_{3}$ & $F_{4}$ & $F_{5}$ & \multirow{2}{*}{$\begin{array}{c}\text { Comprehensive } \\
\text { degrees of } \\
\text { importance }\end{array}$} & \multirow{2}{*}{$\begin{array}{c}\text { Membership } \\
\text { degrees }\end{array}$} \\
\hline & & 0.133 & 0.158 & 0.425 & 0.231 & 0.053 & & \\
\hline$f_{11}$ & 0.648 & 0.0862 & & & & & 0.086 & 0.375 \\
\hline$f_{12}$ & 0.230 & 0.0306 & & & & & 0.030 & 0.625 \\
\hline$f_{13}$ & 0.122 & 0.0162 & & & & & 0.016 & 0.438 \\
\hline$f_{21}$ & 0.333 & & 0.0526 & & & & 0.052 & 0.250 \\
\hline$f_{22}$ & 0.528 & & 0.0834 & & & & 0.083 & 0.625 \\
\hline$f_{23}$ & 0.140 & & 0.0221 & & & & 0.022 & 0.438 \\
\hline$f_{31}$ & 0.199 & & & 0.0846 & & & 0.084 & 0.375 \\
\hline$f_{32}$ & 0.347 & & & 0.1475 & & & 0.147 & 0.875 \\
\hline$f_{33}$ & 0.455 & & & 0.1934 & & & 0.193 & 0.938 \\
\hline$f_{41}$ & 0.400 & & & & 0.0924 & & 0.092 & 0.375 \\
\hline$f_{42}$ & 0.600 & & & & 0.1386 & & 0.139 & 0.500 \\
\hline$f_{51}$ & 0.625 & & & & & 0.0331 & 0.033 & 0.625 \\
\hline$f_{52}$ & 0.238 & & & & & 0.0126 & 0.013 & 0.750 \\
\hline$f_{53}$ & 0.136 & & & & & 0.0072 & 0.007 & 0.250 \\
\hline
\end{tabular}

(5) Comprehensive evaluation and analysis

Put the data in Table 8 into Eq.(1), the anti-terrorism operational risk level $\left(T_{O R L}\right)$ is calculated by the linear weighted synthesis method to be approximately 0.611 .

The lower bound and upper bound values were set as $L B=0.3$ and $U B=0.85$ based on existing data and expert opinion. Because of the fact that $L B \leq T_{O R L} \leq U B$ in the above example, the anti-terrorism capability of the evaluation object should be taken corresponding improvement measures.

It is shown in Table 8, the three sub-factors which have the most influence on the anti-terrorism capability are evacuation facilities, emergency facilities and attack prevention. These three sub-factors are closely related to anti-terrorism personnel. It is well known that the anti-terrorism personal and equipment have an important impact on anti-terrorism capability. The ability of anti-terrorism personnel will determine the success or failure of important building anti-terrorism. Thus, these three sub-factors are more critical to improving anti-terrorism capability of important buildings.

\section{Conclusions}

Based on the actual anti-terrorism case, 14 risk sub-factors belonging to 5 categories which are relative to important building's anti-terrorism capability are identified.And a comprehensive evaluation method was established using FAHP which includes the definition of the relative degrees of importance of the capability factors, the calculation of comprehensive degrees of importance, the definition of the membership degree, and the comprehensive evaluation of the results. This method provides the theoretical principle for anti-terrorism capability evaluation of important buildings. The application result shows

that the evaluation method based on FAHP can be easily applied to evaluae anti-terrorism capability of important buildings. The method will be suitable for the anti-terrorism capability evalution in the building designing process after appropriate modifications.

\section{Acknowledgements}

This work was financially supported by the National University of Defense Technology Science Foundation (U2015209). 


\section{References}

[1] Herzenstein M, Horsky S, Posavac S S. Living with terrorism or withdrawing in terror: Perceived control and consumer avoidance[J]. Journal of Consumer Behaviour, Vol. 14 (2015), p. 228-236

[2] Faiz U R, Paolo V. Terrorism risk and democratic preferences in Pakistan[J]. Journal of Development Economics, Vol.124 (2017), p. 95-106

[3] Stanley T. The local prevention of terrorism: strategy and practice in the fight against terrorism[J], Critical Social Policy, Vol. 36 (2016) , p.736-737

[4] Dearstyne B W. Fighting terrorism, making war: critical insights in the management of information and intelligence[J].Government Information Quarterly, Vol. 22 (2005), p. 170-186.

[5] Schindler J R. Defeating the sixth column: intelligence and strategy in the war on islamist terrorism[J]. Orbis, Vol. 49 (2005), p. 695-712.

[6] Radu M. Terrorism after the cold war: trends and challenges[J]. Orbis, Vol. 46 (2002), p. 275-287.

[7] Sadler M S, Lineberger M, Correll J,et al.. Emotions, Attributions, and Policy Endorsement in Response to the September 11th Terrorist Attacks, Basic and Applied Social Psychology, Vol. 27 (2005) , p. 249-258

[8] LIU Xiao-yan. On reconstruction of anti-terrorism system in Russia after Beslan School Hostage Crisis[J]. Journal of Chinese People's Armed Police Force Academy, Vol. 24 (2008) , p. 86-89

[9] Saaty T L. The analytic hierarchy process[M]. New York: McGraw-Hill, 1980

[10] Tian J, Yan Z F. Fuzzy analytic hierarchy process for risk assessment to general assembling of satellite[J]. Journal of Applied Research and Technology, Vol. 11 (2013) , p. 568-577

[11] LEE W B, LAU H, LIU Zhuo-Zhi, et al.. A fuzzy analytic hierarchy process approach in modular product design[J]. Expert Systems, Vol. 18 (2001) , p. 32-42

[12] Tuysuz F, Kahraman C, Project risk evaluation using a fuzzy analytic hierarchy process: an application to information technology projects[J]. International Journal of Intelligent Systems, Vol. 21 (2006) , p. 559-584.

[13] LI Wei-guo. Application of fuzzy analytic hierarchy process and neural network in power transformer risk assessment[J] Journal of Center South University, Vol. 19 (2012) , p. 982-987 [14] Metin Dagdeviren, Ihsan Yuksel. Developing a fuzzy analytic hierarchy process (AHP) model for behavior-based safety management[J].Information Sciences, Vol. 178 (2008), p. 1717-1733 [15] Kahraman C, Ertay T. A fuzzy optimization model for QFD planning process using analytic network approach[J]. European Journal of Operational Research, Vol. 171 (2006) , p. 390-411 [16] Vaidya O S, Kumarb S. Analytic hierarchy process: an overview of applications[J]. European Journal of Operational Research, Vol. 169 (2006) , p.1-29 